\title{
Are Antidepressants Mood Agents Or Anxiolytic Drugs?
}

\author{
Michel Bourin* \\ Neurobiology of anxiety and mood disorders, University of Nantes, France
}

Received: May 23, 2018; Accepted: June 29, 2018; Published: July 05, 2018

*Corresponding author: Michel Bourin, Neurobiology of anxiety and mood disorders, University of Nantes, France, Email: Michel.bourin@univ-nantes.fr

\begin{abstract}
Many advances have been made in the treatment of depression with the recent discovery of selective serotonin reuptake inhibitors (SSRIs) and mixed serotonin and norepinephrine reuptake inhibitors (SNRIs). Behavioral, electrophysiology, and microdialysis studies have shown that serotonin receptors, mainly the 5-HT1A, 5-HT1B, and 5-HT2C subtypes, play a key role in modulating antidepressant activity. The indirect activation of serotonergic receptors by antidepressants could lead, via an increase in 5-HT concentrations in the synapse of certain brain regions, to the activation of G proteins which would cascade the transcription of neurotrophic factor such as "the brainderived neurotrophic factor "(BDNF). Depression could be considered as an anomaly of transduction mechanisms, this hypothesis needs to be deepened by molecular biology studies.
\end{abstract}

The fact that antidepressants are also active in the treatment of anxiety disorders, questions about the nature of their mechanism in these various pathologies.

Key words: Antidepressants; Serotonin Receptors; Mood Disorders; Anxiety Disorder

\section{Introduction}

Although several hypotheses have been put forward, the aetiology of depression is still poorly defined. The first major theory of depression, i.e., the monoaminergic theory, proposes that this disorder is due in particular to a deficiency of serotonin (5-HT) and norepinephrine (NA) [1, 2, 3, and 4]. Moreover, some molecules that deplete these neurotransmitters, such as reserpine, can induce a depressive state in a small percentage of individuals. However, this simplistic theory cannot explain the pathophysiology of depression by itself since the efficacy of antidepressants is observed clinically after a few weeks of treatment. A second hypothesis based on neurotransmitter receptors has been issued. According to this hypothesis, the depression is due to an abnormal functioning of the monoamine receptors. This receptor disruption could itself be caused by depletion of monoaminergic neurotransmitters. Advances in molecular and cellular biology suggest the role of neurotrophic factors, such as the "brain-derived neurotrophic factor" (BDNF) suggesting a neurodegenerative hypothesis to the pathophysiology of depression $[4,5]$.

In addition, antidepressants are now widely used in the treatment of anxiety disorders, whether generalized anxiety, panic disorder, social anxiety and post-traumatic stress, which makes it possible to wonder about the different nature of their mechanism of action.

\section{Targets for action of antidepressants}

\section{Serotoninergic receptors}

\section{Role of 5-HT1A receptors on antidepressant activity}

Various behavioral, electrophysiological and microdialysis studies have highlighted the role of 5-HT1A receptors in the pharmacological properties of antidepressants. Thus, the effects of the administration of a single dose of antidepressant on an animal model of desperation (forced swimming test) carried out in mice, suggests that the action of imipramine is via the 5-HT1A postsynaptic receptors [6]. Blier and de Montigny [7] in electrophysiology studies have shown that chronic treatment with a selective serotonin reuptake inhibitor (SSRI) induces functional desensitization of 5-HT1A autoreceptors in nuclei of the dorsal raphe. Moreover, although no down-regulation of 5-HT1A autoreceptors in dorsal raphe nuclei has been observed in binding studies [8], microdialysis studies have been conducted $[9,10]$. have shown that chronic treatment with SSRIs causes hypofunction of 5-HT1A autoreceptors. In contrast, postsynaptic 5-HT1A receptors do not react in the same way as 5-HT1A autoreceptors to chronic treatment with SSRIs. Indeed, postsynaptic 5-HT1A receptors, located in the hippocampus, do not undergo desensitization or "down regulation".

The 5-HT1A autoreceptors appear to be a brake on the rapidity of action of antidepressants. Indeed, during the first days of treatment the excess of NA and especially 5-HT intrasynaptic will activate autoreceivers [11]. This phenomenon called negative feedback will slow the system back. Also, a more current research pathway tries to include in the same molecule properties that would increase the speed of action of antidepressants, this would be the case of the blocking of presynaptic 5-HT1A receptors by the (-) pindolol (molecule having antagonistic properties at alpha-adrenergic receptors, 5-HT1A and 5-HT1B). Indeed, clinical studies show that the co-administration of $(-)$ pindolol with an IRSS (fluoxetine or paroxetine) would induce a faster mood improvement in depressed patients [12-16]. This hypothesis remains controversial and is the subject of lively debate [17-19].

\section{Role of 5-HT1B receptors on antidepressant activity}

Pre-clinical studies have shown that serotonin reuptake inhibitors appear to act indirectly on 5-HT1B receptors [8]. This 
notion is also found in the fact that in the elderly mice serotonin reuptake inhibitors lose their activity [20,21], but we know that in these animals age causes a decrease of this subtype of receivers [22]. The 5-HT1B receptor is present both at the presynaptic level [autoreceptors] where it locally controls the release of serotonin, and at the postsynaptic level where it controls the release of other neurotransmitters [dopamine, glutamate, acetylcholine, GABA]. However, behavioral studies [forced swimming test] and microdialysis carried out in mice have shown that according to the brain structure, the IRSS [paroxetine and fluoxetine] activate either the 5-HT1B autoreceptor [at the level of serotoninergic neuronal endings located in the hippocampus but not in the frontal cortex], or the postsynaptic 5-HT1B receptor [23].

As a result, activation of 5-HT1B autoreceptors appears to limit the effects of IRSSs, in contrast to the postsynaptic 5-HT1B receptors that are required for the antidepressant activity of selective serotonin reuptake inhibitors to appear. In an effort to reduce the delay in the action of antidepressants, studies have been conducted using buspirone, a partial agonist of 5-HT1A receptors, in the forced swimming test. These show that coadministration of a selective serotonin reuptake inhibitor with a low dose of buspirone potentiates the antidepressant effect [24] or even microdialysis [25]. Finally, it is likely that the 5-HT1B receptors, in addition to their facilitating action of serotonin release serve as a referral for this neurotransmitter to other serotonin receptors.

\section{Role of other serotonin receptor subtypes on the activity of antidepressants}

Many antidepressants of different chemical classes have only moderate affinity for 5-HT2-like receptors, so there is no obvious correlation between affinity for these receptors and antidepressant activity. However, the high density of 5-HT2C receptors in the cortical and limbic regions suggests their role in anxiety and / or depressive disorders. Several binding or recognition studies using specific antibodies have focused on the precise location of 5-HT2C receptors in the brain [26]. Similarly, in untreated, depressed patients, the density of 5-HT2 receptors at the platelet membranes is increased. If we look at the changes that occur in the density of 5-HT2 receptors in the choroid plexus in rats after repeated administration of antidepressants [fluoxetine and citalopram], it is clear that the number of receptors increases [27]. Other results also reinforce the hypothesis that dysregulation of 5-HT2C receptor function plays an important role in the pathogenesis of anxiety and depressive disorders [28]. Indeed, the mechanisms mediated by the 5-HT2C receptors are hypersensitized in the depression and it is the normalization of this function which could contribute to the antidepressant effect.

It is therefore increasingly likely that the antidepressants we know; whether they are imipramines and derivatives or serotonin reuptake inhibitors, have a different mode of action when it comes to mobilizing different subtypes of serotonergic receptors. It should be noted that most of the experiments described above have been performed after a single antidepressant administration, but it is known that these molecules are intended to be administered over the long term in humans. What link must be established between the mechanism of neurobiochemical action of a molecule and its clinical efficacy in the treatment of depression? This is the challenge of research in pharmacology: among the fifteen or so serotonin receptors identified to date, which one will be more specifically involved? The answer to this question should identify candidates for a faster and more complete anti-depressive activity [30].

\section{Is dopamine the common final route?}

It has been postulated that over 20 years ago dopamine could play a role in depression. In particular, the depression is thought to be due to a decrease in brain concentration of dopamine [30]. Recent studies show that selective serotonin reuptake inhibitors will act on the central dopaminergic system via the D1 and D3 dopamine receptor subtypes. Dopaminergic agonists have been shown to potentiate the antidepressant activity of selective serotonin reuptake inhibitors in the forced swim test [31]. Therefore, three, not two, protagonists [serotonin, norepinephrine, and dopamine] could play a major role in the occurrence of a depressive syndrome. It would therefore be interesting to study the possible mobilization of dopamine during a classic antidepressant treatment, that is to say acting mainly on the two neurotransmitters, serotonin and norepinephrine. Moreover, Gobert et al. [32] showed in microdialysis studies that the concentrations of 5-HT, NA and DA in the same dialysate increased after treatment with fluoxetine.

\section{Antidepressant action on second messengers and genes}

Antidepressants do not only act by inhibiting monoamine reuptake, but also affect neurotransmitter receptors. This stimulation of the receptors causes the activation of transcription factors present inside the nucleus of the cell, via the G proteins. This activation of the transcription factors decreases the synthesis of the receptors: it is the "down regulation". These successive activations stimulate the release of a trophic factor of neuronal origin: BDNF. Does this stimulation account for the increased size of the hippocampus mentioned above, which is a consequence of the action of antidepressants? This is related to the important notion that antidepressants would not only act on neuromodulators but also on neuronal growth factors [1, 5]. Nibuya et al [35] showed in the rat that chronic administration of antidepressants [desipramine, imipramine, fluoxetine, sertraline] increased the BDNF concentration and the corresponding trkB receptor mRNA expression. The expression "cAMP response element binding protein" [CREB] is also increased in the hippocampus. These results would indicate that the administration of an antidepressant, by increasing CREB synthesis, would regulate certain genes such as that encoding BDNF and its trkB receptor. Recently, other pre-clinical studies have confirmed this hypothesis. Thus, Martin et al, [36] showed that the amount of BDNF mRNA was increased after chronic treatment with an antidepressant. Vollmayr et al. [37] in an animal model of depression, the rat-acquired resignation test, show that chronic treatment with antidepressants or with 
seismic therapy prevents the reduction of stress-induced BDNF expression. BDNF would exert its neuronal protective action by autocrine activity on hippocampal neurons and paracrine activity on the neurons that innervate this region. The autocrine activity is very important in depressions associated with severe chronic stress, in which there is a decrease in the concentration of BDNF, leading to atrophy of the hippocampus and, in the worst case, to a reduction in the number of hippocampal neurons [38]. Paracrine activity of BDNF may increase the functions of neurons [serotonergic and noradrenergic] innervating the hippocampus. Indeed, Sklair-Tavron and Nestler [39] have shown that BDNF increases the survival and growth of hippocampal neurons. Animal studies have shown that imipramine antidepressants and their derivatives can behave as compounds that interact with G proteins [40]. Thus, it is plausible to hypothesize that depression could be considered a disorder of the super family of G-proteins coupled to a receptor. This disorder, determined by a genetic defect in some cases, could be expressed at the level of the receptor or alternatively in the $\mathrm{G}$ proteins thus leading to a faulty coupling between the receptor and the $\mathrm{G}$ protein and thus leading to abnormal transduction mechanisms. This hypothesis is to be studied mainly because the 5 -HT1A receptors do not react in the same way to a chronic treatment of antidepressant according to their localization. Indeed, presynaptic 5-HT1A receptors are desensitized after chronic antidepressant treatment, whereas postsynaptic 5-HT1A receptors are not desensitized. The receiver, whatever its location, is nevertheless coded by one and the same gene. Therefore, the differences in antidepressant response would not be due to the receptor protein itself. It is possible that the presynaptic 5-HT1A receptor is coupled to a different $\mathrm{G}$ protein $[\mathrm{Gi}, \mathrm{GB}]$ from that to which the postsynaptic $5-\mathrm{HT} 1 \mathrm{~A}$ receptor is coupled. This suggests that the nature of G-protein coupled to the 5-HT1A receptor might be different from one brain region [dorsal raphe nucleus] to another [frontal cortex, ventral hippocampus]. The use of molecular biology and cell cultures, for example, should shed light on this issue. The pathophysiology of depression should be better studied anyway. What molecular perturbations [receptors, protein G, BDNF and other transcription factors] does it cause? A good experimental model remains to be defined and identified by Knock-Out or transgenic mice.

\section{Therapeutic problems related to antidepressant treatment}

\section{Are there more specific targets for antidepressants?}

At the end of the 1970s, the decrease in the number or sensitivity of beta-adrenergic receptors in the brain appeared to be implicated in antidepressant activity [41]. And since the clinical effect of antidepressants was felt after 15 days, it was thought that there was a rational explanation for antidepressant activity. This decrease also occurs in rats almost three weeks after the start of treatment. Unfortunately, at the moment there are antidepressants that do not lead to "down regulation" of beta receptors and that are clinically active in depression. This is particularly the case of the new antidepressants, that is to say the inhibitors of serotonin retreading. Although "down-regulation" of beta receptors is observed with fluvoxamine, fluoxetine and sertraline, it has not been observed for citalopram and paroxetine.

\section{The dose / effect relationship of antidepressants}

The existence of effect / dose relationships has long been lacking in psychiatry, depriving patients of significant potential benefits. Phase II drug development involves establishing this relationship but it was relatively erratic. With tricyclics in particular, a significant increase in the dose leads to inefficiency following a U-shaped effect / dose curve. Today, the proof of an effect / dose relationship has been established for two molecules: paroxetine and venlafaxine. . Like paroxetine [42], venlafaxine is expected to have a low serotonin reuptake inhibitory dose and a norepinephrine reuptake inhibitor [43]. It is thus considered that starting at $150 \mathrm{mg}$ and above, venlafaxine mainly inhibits the reuptake of norepinephrine [6]. Thus, for paroxetine, increasing

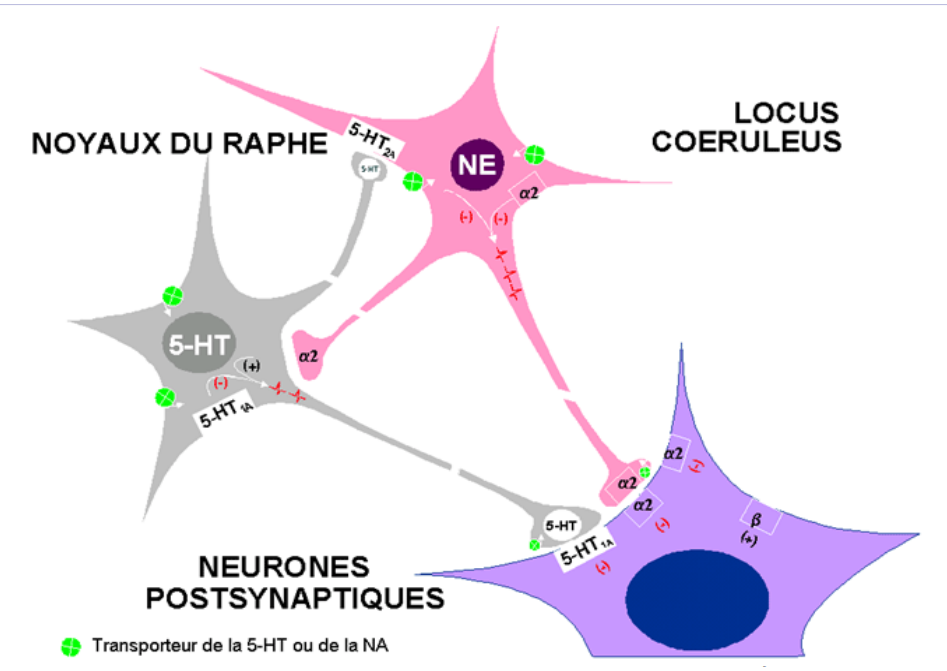

[+] ou [-] indique une action excitatrice ou inhibitrice au niveau des récepteurs.

Figure1: Mutual interactions between dorsal Raphe serotoninergic neurons and Locus Coeruleus noradrenergic neurons and their respective projections across the brain. 
the daily dosage from 20 to $40 \mathrm{mg}$ / day significantly increases the proportion of responders. Although this dose increase is limited by the occurrence of side effects, the dose / effect relationship allows the patient to be offered a dose increase rather than an interruption of treatment and the change by another molecule. The establishment of a dose-response relationship for some antidepressants is a significant contribution to the treatment of depression.

\section{Inter-relationships between brain structures / neurotransmitters}

Knowledge of interrelationships between neurotransmission systems is very important. Activation or inhibition of one system is not without effect on others. For example, the noradrenergic and serotoninergic system interacts with each other. Indeed, serotoninergic cell bodies [present in raphe nuclei] and noradrenergic cell bodies [present in the region of the locus coeruleus] emit mutually projections from one to the other [Figure 1]. Thus, we find serotoninergic heteroreceptors [5HT2A] on the endings of noradrenergic neurons as well as noradrenergic heteroreceptors [alpha 1] on the cell bodies of serotoninergic neurons. The alpha 2 noradrenergic receptor can itself be an autoreceptor or a heteroreceptor. Thus, activation of the alpha 2 noradrenergic autoreceptors of the locus coeruleus contributes to the reduction of the concentration of noradrenaline and serotonin in the frontal cortex via a decrease in excitatory noradrenergic fiber activity, mediated by postsynaptic alpha 1 noradrenergic receptors. Localized in the cell bodies of the neurons of the raphe nuclei. In addition, the activation of alpha 2 adrenergic autoreceptors present at the end of adrenergic neurons in the raphe nuclei may also inhibit the activity of serotoninergic cell bodies [32].

\section{Evolution of the antidepressant concept}

The concept of antidepressant is evolving gradually since these molecules are used successfully to treat other mental pathologies than depression. Clomipramine was the first to prove an activity in the treatment of obsessive compulsive disorder [OCD] while other imipramines and derivatives are not effective. In fact, its desmethyl-clomipramine metabolite is a potent inhibitor of serotonin reuptake but also norepinephrine. The combined results of clomipramine and desmethylclomipramine on the inhibition of serotonin reuptake are much greater than those of other tricyclics. Other selective serotonin reuptake inhibitors, such as fluoxetine, fluvoxamine, sertraline and paroxetine, have also been shown to be effective in the treatment of OCD. Their effectiveness in treating this condition is clearly not related to their antidepressant properties as these drugs reduce obsessivecompulsive symptoms in patients who are not depressed.

As early as the 1960s, several studies have demonstrated the efficacy of MAOIs in anxio-phobic states, but the difficulty of using these derivatives has led them to use them only in severe cases or even to abandon them. These results have been confirmed more recently and new studies have been developed thanks to the use of potentially less toxic derivatives such as the MAO-specific inhibitors A. Liebowitz, in 1992 [49], took stock of the various controlled trials or not, versus placebo and concludes that these molecules have a particularly interesting efficacy in the treatment of social phobias.

It was Klein and Fink who first observed that imipramine was able to prevent panic attacks, later Klein [50] showed that imipramine was effective in the treatment of phobias with panic attacks but not effective in pure phobias. These observations led to the treatment of subjects with panic attacks with low doses of imipramine for preventive purposes, the high doses exaggerating the phenomenon. The dose is increased in steps until, after three months; doses of imipramine are similar to those usually used in depression.

Finally, in a recent study Rickels et al. [51] showed that imipramine and trazodone were effective in the treatment of generalized anxiety. Imipramine results in better results than trazodone and diazepam compared to placebo after 6 and 8 weeks

This work confirms earlier work that had been conducted in patients with anxio-depressive pathology $[52,53]$. Now the various IRS have received their marketing authorization in generalized anxiety and other anxiety disorders.

The fact that antidepressants are active in the treatment of anxiety disorders led us to seek the explanation of their mechanisms of action in these pathologies.

It turns out that the 5-HT2A receptors can participate in this activity .It seems more and more obvious that this action would be exercised at the amygdala, a cerebral structure that seems to be a "Filter" on the perception of emotions and which is rich in 5-HT2A receptors.

\section{Conclusion}

It is important to recall a now admitted fact that depression must be conceptualized as a recurrent illness that requires treatment at the time of the episode and in the long run to avoid relapse. Indeed, all antidepressants are effective in the acute phase of the disease and the prevention of relapses requires continuation of long-term treatment and the same dosage. Finally, the neurobiological bases of relapses and recurrences are, to date, unknown. Relapses and recurrences likely involve complex mechanisms of pre- and post-synaptic regulation. While considerable progress has been made recently, the treatment of depression needs to be further improved.

High hopes lie in the research that is now aimed at supporting the hypothesis that molecules that increase the release of norepinephrine and / or serotonin may make subjects less sensitive to life events and reduce the risk of depressive relapse. Lastly, it should also be noted that there are no antidepressants that can improve the anhedonia that is inherent to depressive illness. Moreover, the use of antidepressants now largely exceeds the treatment of depression and this therefore raises the problem of knowing what is actually an antidepressant compared to conventional anxiolytics such as benzodiazepines, or even buspirone. It is possible that we do not yet have at our disposal "real antidepressants" insofar as the derivatives that we currently use are active in the first weeks of treatment in a depressive, on 
the anxiety disorders and the disorders of sleep associated with depression and that it takes 6 weeks to get a clear improvement in mood. Will the new antidepressants be drugs that can, through an action on transduction signals such as G proteins, modify mood disorders? Are classic antidepressants only anxiolytics? It is possible that in the next decade, a new classification of psychotropic drugs is based on the activity of drugs on mental diseases better identified. This would be a good return since these drugs have been shown to be useful for better understanding the neurobiology of mental disorders.

\section{References}

1. Massart R, Mongeau R, Lanfumey L. Beyond the monoaminergic hypothesis: neuroplasticity and epigenetic changes in a transgenic mouse model of depression. Philos Trans R Soc Lond B Biol Sci. 2012;367(1601):2485-2494. doi: 10.1098/rstb.2012.0212

2. Coppen A. Biochemistry of affective disorders. Br J Psychiatry. 1967;113(504):1237-1264.

3. Schildkaut JJ. The catecholamine hypothesis of affective disorders: a review of supporting evidence. Am J Psychiatry. 1965;122(5):509522.

4. Numakawa T, Odaka H, Adachi N. Actions of Brain-Derived Neurotrophic Factor and Glucocorticoid Stress in Neurogenesis. Int J Mol Sci. 2017;18(11):pii: E2312. doi: 10.3390/ijms18112312

5. Phillips C. Brain-Derived Neurotrophic Factor, Depression, and Physical Activity: Making the Neuroplastic Connection. Neural Plast. 2017:7260130. doi: 10.1155/2017/7260130

6. Redrobe JP, Mac Sweeney CB, Bourin M. The role of 5-HT1A and 5-HT1B receptors with antidepressants drugs in the mouse forced swimming test. Eur J Pharmacol. 1996;318(2-3):213-220.

7. Blier $P$, De Montigny C. Electrophysiological investigations on the effect of repeated zimelidine administration on serotonergic neurotransmission in the rat. J Neurosci. 1983;3(6):1270-1278.

8. Le Poul E, Boni C, Hanoun, Laporte AM, Laaris N, Chauveau J. Differential adaptation of brain 5-HT1A and 5-HT1B receptors and 5-HT transporter in rats treated chronically with fluoxetine. Neuropharmacology. 2000;39(1):110-122.

9. Bel N, Artigas F. Chronic treatment with fluvoxamine increase extracellular serotonin in frontal cortex but not in raphe nuclei. Synapse. 1993;15:243-245.

10. Gardier AM, Malagie I, Trillat AC, Jacquot C, Artigas F. Role of 5-HT1A autoreceptors in the mechanism of action of serotoninergic antidepressant drugs : recent finding from in vivo microdialysis studies. Fundam Clin Pharmacol. 1996;10(1):16-27.

11. Andrade R, Huereca D, Lyons JG, Andrade EM, McGregor KM. 5-HT1A Receptor-Mediated Autoinhibition and the Control of Serotonergic Cell Firing. ACS Chem Neurosci. 2015;6(7):1110-1115. doi: 10.1021/ acschemneuro.5b00034

12. Artigas F, Perez V, Alvarez E. Pindolol induces a rapid improvement of depressed patients treated with serotonin reuptake inhibitors. Arch Gen Psychiatry. 1994;51(3):248-251.

13. Artigas F, Romero L, De Montigny C, Blier P. Acceleration of the effect of selected antidepressant drugs in major depression by 5-HT1A antagonists. Trends Neurosci. 1996;19(9):378-383.
14.Blier P, Bergeron R. Effectiveness of pindolol with selected antidepressant drugs in the treatment of major depression. J Clin Psychopharmacol. 1995;15(3):217-222.

15. Perez V, Gilaberte I, Faries D, Alvarez E, Artigas F. Randomised, double-blind, placebo-controlled trial of pindolol in combination with fluoxetine antidepressant treatment. Lancet. 1997;349(9065):15941597.

16.Zanardi R, Artigas F, Franchini L, Sforzini L, Gasperini M, Smeraldi E, Perez J. How long should pindolol be associated with paroxetine to improve the antidepressant response?. J Clin Psychopharmacol. 1997;17(6):446-450.

17. Berman RM, Darnell AM, Miller HL, Anand A, Charney DS. Effect of pindolol in hastening response to fluoxetine in the treatment of major depression: a double-blind, placebo-controlled trial. Am J Psychiatry. 1997;154(1):37-43.

18. Berman RM, Anand A, Cappiello A, Miller HL, Hu XS, Oren DA, et all. The use of pindolol with fluoxetine in the treatment of major depression: final results from a double-blind, placebo-controlled trial. Biol Psychiatry. 1999 ;45(9):1170-1177.

19. Tome MB, Isaac MT, Harte R, Holland C. Paroxetine and pindolol: a randomized trial of serotonergic autoreceptor blockade in the reduction of antidepressant latency. Int Clin Psychopharmacol. 1997;12(2):81-89.

20. Bourin M, Colombel MC, Nizard J, Hascoët M, Baker GB. Evaluation of efficacies of different classes of antidepressants in the forced swimming test in mice at different ages. Prog Neuropsychopharmacol Biol Psychiatry. 1998;22(2):343-351.

21. David DJP, Bourin M, Hascoët M, Colombel MC, Baker GB, Jolliet P. Comparison of antidepressant activity in 4- and 40- week old male mice in the Forced Swimming test: involvement of 5-HT1A and 5-HT1B receptors in old mice. Psychopharmacology (Berl). 2001;153(4):443449.

22. Gozlan H, Daval G, Verge D, Spampinato U, Fattaccini CM, Gallissot MC, et all. Aging associated changes in serotoninergic and dopaminergic pre- and postsynaptic neurochemical markers in the rat brain. Neurobiol Aging. 1990;11(4):437-449.

23. Gardier AM, Trillat AC, Malagie I, David D, Hascoet M, Colombel MC, et all. Récepteurs 5-HT1B de la sérotonine et effets antidépreseurs des inhibiteurs de recapture sélectifs de la sérotonine. CR Acad Sci 2001;324:433-441.

24. Redrobe JP, Bourin M. Dose-dependent influence of buspirone on the activities of selective serotonin reuptake inhibitors in the mouse forced swimming test. Psychopharmacology 1998;138:198-206.

25. Gobert A, Rivet JM, Cistarelli L, Melon C, Millan MJ. Buspirone modulates basal and fluoxetine-stimulated dialysate levels of dopamine, noradrenaline and serotonin in the frontal cortex of freely moving rats: activation of serotonin1A receptors and blockade of alpha2-adrenergic receptors underlie its actions. Neuroscience. 1999;93(4):1251-1262.

26. Mengod G, Pompeiano M, Martinez-Mir MI, Palacio JM. Localization of the mRNA for the 5-HT2 receptor by in situ hybridisation histochemistry. Correlation with the distribution of receptor sites. Brain Res. 1990;524(1):139-143. 
27. Laasko A, Palvimaki EP, Kuoppamaki M, Syvalathi E, Hietala J. Chronic citalopram and fluoxetine treatments upregulate 5 -HT2C receptors in the rat choroids plexus. Neuropsychopharmacology. 1996;15(2):143151. DOI: 10.1016/0893-133X(95)00176-E

28. Moreau JL, Jenck Bös M, Jenck F, Martin JR, Mortas P, Wichmann J. 5-HT2C receptor agonists exhibit antidepressant-like properties in the anhedonia model of depression in rats. Eur Neuropsychopharmacol. 1996;6(3):169-175.

29. Segi-Nishida E. The Effect of Serotonin-Targeting Antidepressants on Neurogenesis and Neuronal Maturation of the Hippocampus Mediated via 5-HT1A and 5-HT4 Receptors. Cell Neurosci. 2017;11:142. doi: $10.3389 /$ fncel.2017.00142

30.Randrup A, Munkvad I, Fog R. Mania, depression, and brain dopamine. In: Essman WB \& Valzelli L Eds: Current developments in psychopharmacology. New York: Spectrum Publications, 1975: 207209.

31. Renard CE, Fiocco AJ, Clenet F, Hascoët M, Bourin M. Is dopamine implicated in the antidepressant-like effect of selective serotonin reuptake inhibitors in the mouse forced swimming test? Psychopharmacology. 2001;159(1):42-50. DOI: 10.1007/ s002130100836

32. Gobert A, Rivet M, Cistarelli L, Melon C, Millan J. $\alpha 2$-adrenergic receptor blockade markedly potentiates duloxetine- and fluoxetine-induced increases in noradrenaline, dopamine, and serotonin levels in the frontal cortex of freely moving rats. J Neurochem. 1997;69(6):26162619

33. Murck H, Frieboes RM, Antonijevic IA, Steiger A. Distinct temporal pattern of the effects of the combined serotonin-reuptake inhibitor and 5-HT1A agonist EMD 68843 on the sleep EEG in healthy men. Psychopharmacology. 2001;155(2):187-192.

34.Van Reeth O, Olivares E, Zhang Y, Tripathi B, Turek FW. Chronobiotic effects of gepirone, a potential antidepressant with 5-HT1A receptor partial agonist properties. Behav Pharmacol. 1999;10(2):119-130.

35. Nibuya M, Neslter EJ, Duman RS. Chronic antidepressantadministration increases the expression of camp response element binding protein [CREB] in rat hippocampus. J Neurosci. 1996;16(7):2635-2372.

36. Martin A, Kaufmann J, Charney D. Pharmacotherapy of early-onset depression. Update and new directions. Child Adolesc Psychiatry Clin. 2000;9(1):135-157.

37. Vollmayr B, Faust H, Lewicka S, Henn FA. Brain-derivated neurotrophicfactor $[\mathrm{BDNF}]$ stress response in rats bred for learned helplessness. Mol Psychiatry. 2001;6(4):471-474. DOI: 10.1038/sj.mp.4000907

38. Smith MA, Makino S, Kvetnanasky R, Post RM. Stress alters the express of brain-derived neurotrophic factor and neurotrophin-3 mRNAs in the hippocampus. J Neurosci. 1995;15(3):1768-1777.

39. Sklair-Tavron L, Nestler EJ. Opposing effects of morphine and the neurotrophins, NT-3, NT-4, and BDNF, on locus coeruleus neurons in vitro. Brain Res. 1995;702(1-2):117-125.

40. Moor M, Honegger UE, Weissman UN. Organospecific qualitative changes in the phospholipid composition of rats after chronic administration of the antidepressant drug, desipramine. Biochem Pharmacol. 1987;37(10):2035-2039.
41. Sulser F, Vetulani J, Mobley PL. Mode of action of antidepressant drugs. Biochem Pharmacol. 1978;27(3):257-261.

42. Redrobe JP, Bourin M, Colombel MC, Baker GB. Psychopharmacological profile of the selective serotonin reuptake inhibitor, paroxetine: implication of noradrenergic and serotonergic mechanisms. J Psychopharmacol. 1998;12(4):348-355. DOI: 10.1177/026988119801200404

43. Redrobe JP, Bourin M, Colombel MC, Baker GB. Dose-dependent noradrenergic and serotoninergic properties of venlafaxine in animal models indicative of antidepressant activity. Psychopharmacology. 1998;138(1):1-8.

44. Sheline YI, Sanghavi M, Mintun MA, Gado MH. Depression duration but not age predicts hippocampal volume loss in medically healthy women with recurrent major depression. J Neurosc. 1999;19(12):5034-5043.

45. Sheline YI, Wany P, Gado MH, Csernansky JG, Vannier MW. Hippocampal atrophy in recurrent major depression. Proc Natl Acad Sci USA. 1996;93(9):3908-3913.

46. Bremner JD, Randall P, Scott TM, Bronen RA, Seibyl JP, Southwick SM, Delaney RC, McCarthy G, Charney DS, Inis RB. MRI-based measurement of hippocampal volume in patients with combat-related post-traumatic disorder. Am J Psychiatry. 1995;152(7):973-981. DOI: 10.1176/ajp.152.7.973

47. Bremner JD, Narayan M, Anderson ER, Staib LH, Miller H, Charney DS. Smaller hippocampal volume in major depression. Am J Psychiatry. 2000;157(1):115-117. Doi:10.1176/ajp.157.1.115

48.Steffens D, Byrum CE, McQuoid DR, Greenberg Dl, Payne ME, Blichington TF, MacFall JR, Krishnan KRR. Hippocampal volume in geriatric depression. Biol Psychiatry. 2000;48(4):301-309.

49. Liebowitz MR. Reversible MAO inhibitors in social phobia, bulimia and other disorders. Clin Neuropharm. 1992;15[suppl 1]:434A-435A.

50. Klein DF. Anxiety reconceptualized. In: Klein DF, Rabkin J. Eds. Anxiety: New research and changing concepts, New-York, Raven Press. 1981:235-263.

51. Rickels K, Downing R, Schweizer E, Hassman H. Antidepressants for the treatment of generalized anxiety disorder. A placeo-controlled comparison of imipramine, trazodone and diazepam. Arch Gen Psychiatry. 1993;50(11)884-895.

52. Montoya A, Bruins R, Katzman MA, Blier P. The noradrenergic paradox: implications in the management of depression and anxiety. Neuropsychiatr Dis Treat. 2016;12:541-557

53. Sild M, Ruthazer ES, Booij L. Major depressive disorder and anxiety disorders from the glial perspective: Etiological mechanisms, intervention and monitoring. Neurosci Biobehav Rev. 2017pii:S0149-7634[17]30472-4. Doi: 10.1016/j. neubiorev.2017.09.014

54. Clinard CT, Bader LR, Sullivan MA, Cooper MA. Activation of 5-HT2a receptors in the basolateral amygdala promotes defeatinduced anxiety and the acquisition of conditioned defeat in Syrian hamsters. Neuropharmacology. 2015;90:102-112. DOI: 10.1016/j. neuropharm.2014.11.016 